\title{
Complexation of calcium ions by humic and fulvic acids
}

\author{
A. Ouatmane ${ }^{1}$, M. Hafidi ${ }^{2}$, M. El Gharous ${ }^{3}$ and J.C. Revel ${ }^{4}$ \\ ${ }^{1}$ Fac. Sciences et Techniques, BP. 523, Beni-Mellal, Maroc \\ ${ }^{2}$ Fac. Science Semlalia, Marrakech, Maroc \\ ${ }^{3}$ INRA, Settat BP. 589, Maroc \\ ${ }^{4}$ ENSA Toulouse, Av. Muret, BP. 145, France
}

\begin{abstract}
Complexe formation between humic matter and ions in soil can increase the solubility of several nutrients and consequently their biodisponibility. To give a better insight about such complexation, humic and fulvic acid were extracted from farmyard manure and their ability to complexe calcium ions was characterized experimentally through simultaneous potentiometric and conductimetric titration with $\mathrm{NaOH}$ and $\mathrm{Ca}(\mathrm{OH})_{2}$. Complexation power was assessed by $\mathrm{pH}$ Statconductimetric titration. Results shows that complexation of calcium by humic and fulvic acid was detected only at slightly acid, neutral and basic $\mathrm{pH}$ and complexation power was favored by increasing $\mathrm{pH}$. The amount of protons released following calcium complexation by humic and fulvic acid was determined for each $\mathrm{pH}$ studied and the nature of functional groups involved in complexation was discussed.
\end{abstract}

\section{Introduction}

Humus content is one of the most important factor determining the productivity of soil because of multiples effects of humic substances such as release of plant nutrients, improvement of soil physical and biological conditions, and increasing the efficiency of fertilizer $[1,2]$. This last effect have been largely attributed to the ability of humic substances to control the solubility and biodisponibility of several chemical element via complexation process $[3,4]$. In calcareous soils, calcium is a reactive and ubiquitously concentrated cation witch can decrease the biodisponibility of several micronutrients (e.g. $\mathrm{Fe}^{++}, \mathrm{Zn}^{++}, \mathrm{Cu}^{++}$) as well as main nutrients $(\mathrm{P})$ through the formation of insoluble calcium phosphates. Thus, calcium complexation by humic matter can play a decisive effect on phosphorus dynamic by increasing apatite solubilization [5,6] and limiting phosphorus sorption and fixation $[7,8]$. It is also found that calcium complexing power of humic substances is well correlated with improved phosphate nutrition in calcareous soils [9]. Such improvement is however still difficult to interpret since humic substances can increase phosphorus solubility also as a result of competitive adsorption on phosphorus fixation sites [10]. Further, positive effect of calcium complexation on phosphorus seems to be dependent on soil $\mathrm{pH}$ [11]. To give a deeper insight about such effect the investigation reported here is a preliminary study to characterize the complexation of calcium by humic substances using potentiometric and conductimetric titration.

\section{Materials and methods}

\section{Preparation of humic and fulvic acids}

Humic matter was extracted from composted farmyard manure using $\mathrm{KOH} 0.1 \mathrm{~N}(1 / 50: \mathrm{W} / \mathrm{V})$ by agitation at $400 \mathrm{t} / \mathrm{min}$, for $16 \mathrm{H}$. After centrifugation for $30 \mathrm{~min}$ at $12000 \mathrm{t} / \mathrm{min}$, the supernatant was carefully recovered, filtered through $0.45 \mu \mathrm{m}$ membrane and then adjusted to $\mathrm{pH} 2$ by $\mathrm{HCl} 1 \mathrm{~N}$. The solution obtained was allowed to coagulate for $24 \mathrm{H}$ at $4{ }^{\circ} \mathrm{C}$ then it was centrifuged as above. Fulvic acid (FA) was recovered directly and humic acid (HA) was washed twice with deionised water and then dissolved in $\mathrm{NaOH} 0.01 \mathrm{~N}$. Excess cation were eliminated by repeated dialysis using a Spectra Port type C MWCO 100 membrane. Humic and fulvic solutions were then brought to one liter with deionised water. Final $\mathrm{pH}$ were 7.8 and 3.7, for humic and fulvic acid respectively. Humic matter content was determined by oxidation with $\mathrm{KMnO}^{4} 0.1 \mathrm{~N}$.

\section{Calcium complexation}

Citric acid was chosen as reference because his reaction with calcium is well known. Titration was performed with $100 \mathrm{~mL}$ of citric acid $0.25 \mathrm{mM}$, humic acid $(25 \mathrm{mg} / \mathrm{L})$ and fulvic acid ( $25 \mathrm{mg} / \mathrm{L})$ initially adjusted to $\mathrm{pH} 3.5$ with $\mathrm{HCl}$ $0.1 \mathrm{~N}$. Each acid was then neutralized stepwise using $\mathrm{NaOH}$ and $\mathrm{Ca}(\mathrm{OH})_{2}$ at $0.040 \mathrm{~N}$ under $\mathrm{N}_{2}$ bubbling. Titration speed of $50 \mu \mathrm{L} / 30$ seconds was chosen so that the $\mathrm{pH}$ and the conductivity becomes stable after each increment of base added. The end of titration is indicated by a sharp increase of conductivity due to execess of $\mathrm{OH}^{-}$ion. Calcium complexation was also monitored at constant $\mathrm{pH}$ over a wide range of $\mathrm{pH}$ values: 4.5 to 9.5 . Samples of $25 \mathrm{mg}$ humic 
acid or fulvic acid were adjusted to a starting $\mathrm{pH}$ and brought to a volume of $100 \mathrm{~mL}$. For each $\mathrm{pH}$ studied, calcium was added by increments of $50 \mu \mathrm{L}$ of $\mathrm{CaCl}_{2} 0.2 \mathrm{~N}$ using Eppendorf pipette while the $\mathrm{pH}$ was kept constant during titration by an automatic addition of $\mathrm{Ca}(\mathrm{OH})_{2}$. The end of titration is indicated by a change in the slope of conductimetric curve witch becomes parallel to conductimetric curve of deionised water used as control.

For all titrations and complexation experiments a titrator Mettler DL 21 was used. Its vessel is equipped with four ports: a $\mathrm{pH}$ combination electrode, a conductivimeter electrode, a $\mathrm{N}_{2}$ bubbling tube and a port which could be opened for addition of reagents $\left(\mathrm{CaCl}_{2}\right.$ in calcium complexation). The conductivimeter used was a Mettler YSI 32. Agitation was controled by the titrator.

\section{Results and discussion}

\section{Potentiometric and conductimetric titration}

For citric acid, conductimetric and potentiometric variations were similar up to $\mathrm{pH}$ 4.5. They were determined by the neutralization of $\mathrm{H}^{+}$and its replacement by $\mathrm{Na}^{+}$or $\mathrm{Ca}^{++}$of low equivalent conductivity (Fig. 1). From $\mathrm{pH} 4.5$ the complexation of calcium by citric acid is shown by a release of $\mathrm{H}^{+}$as increase of $\mathrm{pH}$ was slowed compared to that of $\mathrm{NaOH}$ titration. The absence of any conductivity increase in the case of $\mathrm{Ca}(\mathrm{OH})_{2}$ titration suggests that added calcium was complexed. Further, a slight steady decrease of conductivity was observed around $\mathrm{pH} 4.8$ and 6.2. It could be attributed to dissociation and neutralization of the first and the second $\mathrm{COOH}$ functional groups of citric acid, respectively. Beyond $\mathrm{pH} 9\left(D^{\prime}\right)$ the sharp increase in conductivity is due to $\mathrm{OH}^{-}$ excess as complexation and neutralization were completed. The amount of $\mathrm{NaOH}$ and $\mathrm{Ca}(\mathrm{OH})_{2}$ consumed by citric acid at the end of neutralization are equal $\left(D\right.$ and $\left.D^{\prime}\right): 80 \mu$ eq $\mathrm{H}^{+}$. Total acidity of citric acid solution used is $75 \mu \mathrm{eq} \mathrm{H}^{+}$. This difference could be attributed to the error in determining the end point. Titration of HA and FA are shown on the same figure. The bevaviour of those acids is close to that of citric acid. Until $\mathrm{pH} 4.5$, potentiometric and conductimetric variations are the same with the two bases. They suggest the absence of calcium complexation. However, as titration progresses differences appear as there was a release of protons in the case of $\mathrm{Ca}(\mathrm{OH})_{2}$ titration. Also, the conductivity increases only slightly with comparison to $\mathrm{NaOH}$ titration. This suggest that a part of added calcium was complexed. Similar results were obtained by Arai and Kumada [12] and Brun et al. [13]. Beyond $\mathrm{pH} 10.5\left(D^{\prime}\right)$ the complexation becomes negligible and there is a sharp increase in conductivity. For $\mathrm{NaOH}$ titration the fast increase of conductivity was unregistered at $\mathrm{pH} 10(D)$. It is equivalent to the end of titration. The amount of $\mathrm{Ca}(\mathrm{OH})_{2}$ consumed was superior to that of $\mathrm{NaOH}$ (point $D^{\prime}$ via $D$ ). Hence, complexation of calcium by humic and fulvic acids should release some acids. According to Aplincourt et al. [14], Piccolo and Stevenson

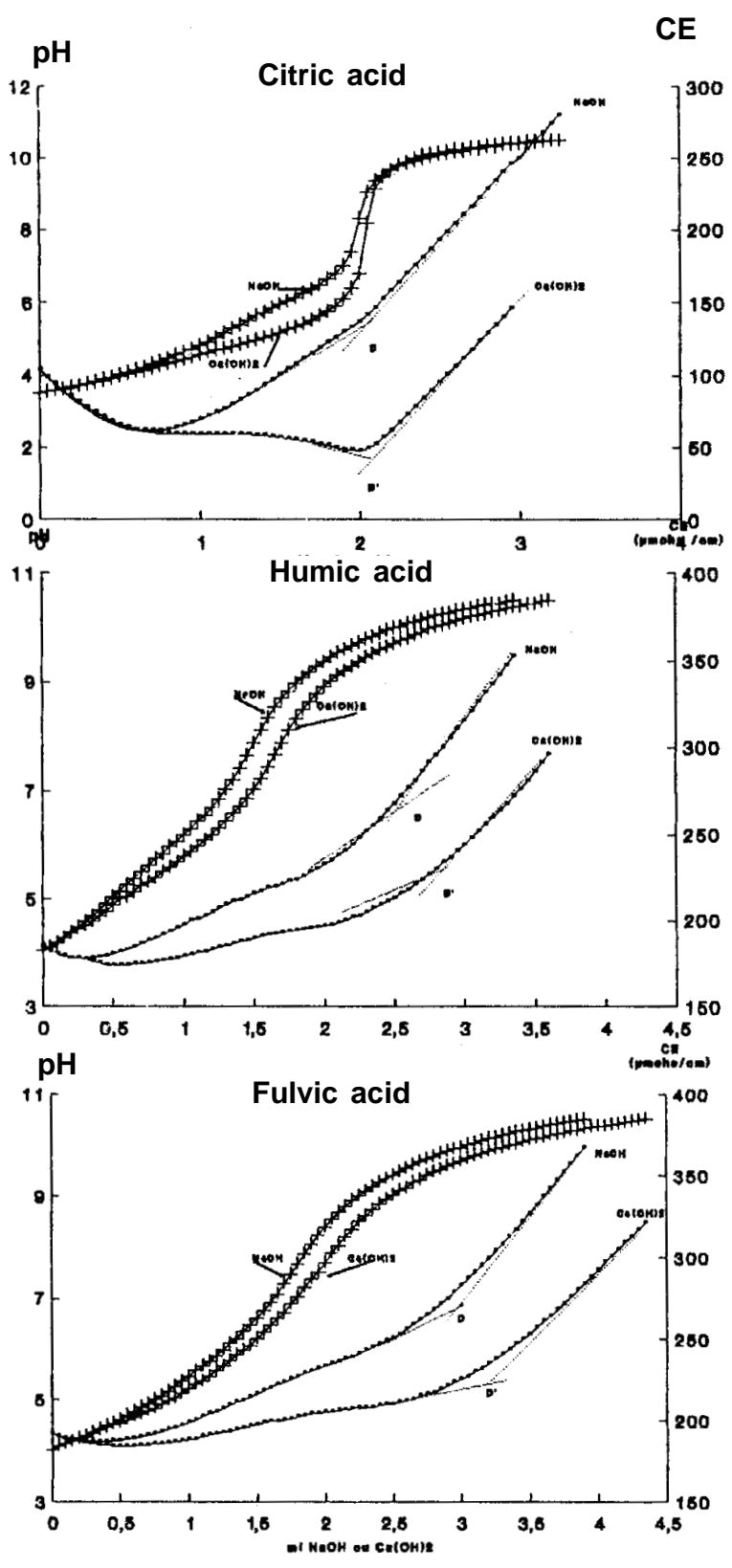

Figure 1. Potentiometric and conductimetric curves of citric acid, humic and fulvic acids.

[15] and Khalili [16], complexation of calcium with humic substances induce some structural modifications which could bring about some new functional groups and consequently an additional acidity. This hypothesis agrees with our finding. Total acidity based on the amount of $\mathrm{Ca}(\mathrm{OH})_{2}$ consumed

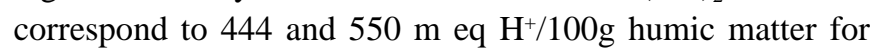
humic and fulvic acid respectively. 
Table I. Results of calcium complexation (a: meq Ca++ complexed by $100 \mathrm{~g}$ of humic matter, b: mole $\mathrm{H}^{+}$released for each mole $\mathrm{Ca}^{++}$complexed).

\begin{tabular}{|c|c|c|c|c|c|}
\hline & 5.5 & 6.5 & $\begin{array}{l}p H \\
7.5\end{array}$ & 8.5 & 9.5 \\
\hline \multicolumn{6}{|c|}{ Humic acid } \\
\hline $\mathrm{a}$ & $99 \pm 6$ & $127 \pm 6$ & $145 \pm 6$ & $165 \pm 6$ & $175 \pm 6$ \\
\hline $\mathrm{b}$ & $0.52 \pm 0.04$ & $0.52 \pm 0.03$ & $0.42 \pm 0.01$ & $0.36 \pm 0.01$ & $0.27 \pm 0.01$ \\
\hline \multicolumn{6}{|c|}{ Fulvic acid } \\
\hline $\mathrm{a}$ & $85 \pm 6$ & $131 \pm 6$ & $140 \pm 6$ & $168 \pm 6$ & $178 \pm 6$ \\
\hline $\mathrm{b}$ & $0.52 \pm 0.04$ & $0.41 \pm 0.02$ & $0.33 \pm 0.02$ & $0.23 \pm 0.01$ & $0.29 \pm 0.01$ \\
\hline
\end{tabular}

\section{pH- Stat- Complexation}

Results of calcium complexation at fixed $\mathrm{pH}$ for humic and fulvic acid are shown in figures 2 and 3, respectively. Except for $\mathrm{pH} 4.5$ all curves show a first region where conductivity increases slightly and a second region where conductivity variations are equal to those of deionised water which suggest that complexation has been completed. Release of protons was also limited to the first region. The amount of calcium complexed and protons released are given by table I. Values obtained reflect $\mathrm{pH}$ dependency of calcium complexation by humic and fulvic acid: complexation was negligible at $\mathrm{pH} 4.5$ but it increases as $\mathrm{pH}$ increases. Similar results were found by others authors $[5,17,18]$. The amount of released protons decreases as $\mathrm{pH}$ increases. The highest amount found was 0.56 mole $\mathrm{H}^{+}$/ mole of calcium and it is however less than the theoretical value of 2 moles $\mathrm{H}^{+}$for each mole of calcium complexed. So, complexation of calcium by humic and fulvic acid should involve mainly strong acidic groups. The existence of such functional groups was confirmed by the first derivative of potentiometric curve obtained with $\mathrm{NaOH}$ for humic and fulvic acid (Fig. 4). In fact, the first $\mathrm{pKa}$ is around 4 (pKa1). It corresponds to strong $\mathrm{COOH}$ groups. The second $\mathrm{pKa}$ around 6.2 is attributed to week $\mathrm{COOH}$ groups. A possible $\mathrm{OH}$ phenolic groups is however not clearly present here as it is difficult to found by direct titration.

For fulvic acid the shape of curve suggests the existence of several functional groups with close pKa.

In all case, for the range of $\mathrm{pH}$ studied, the protons released are attributed to dissociation of week $\mathrm{COOH}$ and to very week $\mathrm{COOH}$ and phenolic $\mathrm{OH}$ groups. Further, strong acidic $\mathrm{COOH}$ should be quantitatively the most important but, as results shows, formation of $\mathrm{Ca}$-humic and $\mathrm{Ca}$-fulvic complex are not possible at acidic $\mathrm{pH}$ probably due to higher competitively of $\mathrm{H}^{+}$compared to that of $\mathrm{Ca}^{++}$for dissociated $\mathrm{COO}^{-}$[19]. Stability of calcium humate and calcium fulvate at higher $\mathrm{pH}$ is also still difficult to interpret. It is believed that configuration changes in HA and FA occurs at basic $\mathrm{pH}$ and allows stability of the complexes formed between humic acid, fulvic acid and bivalent cations [14].

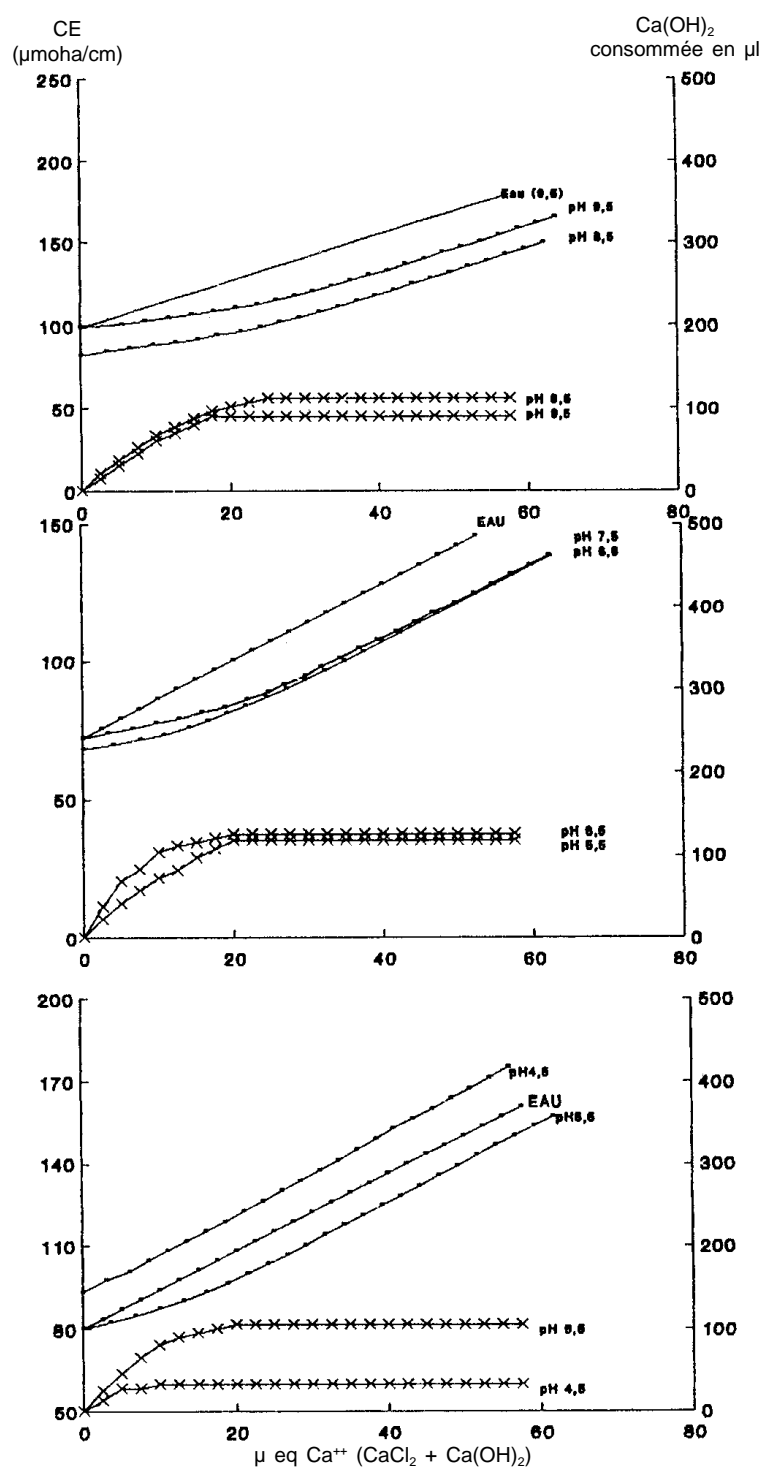

Figure 2. Conductimetric and $\mathrm{Ca}(\mathrm{OH})_{2}$ consumption curves of humic acid at different $\mathrm{pH}$. 

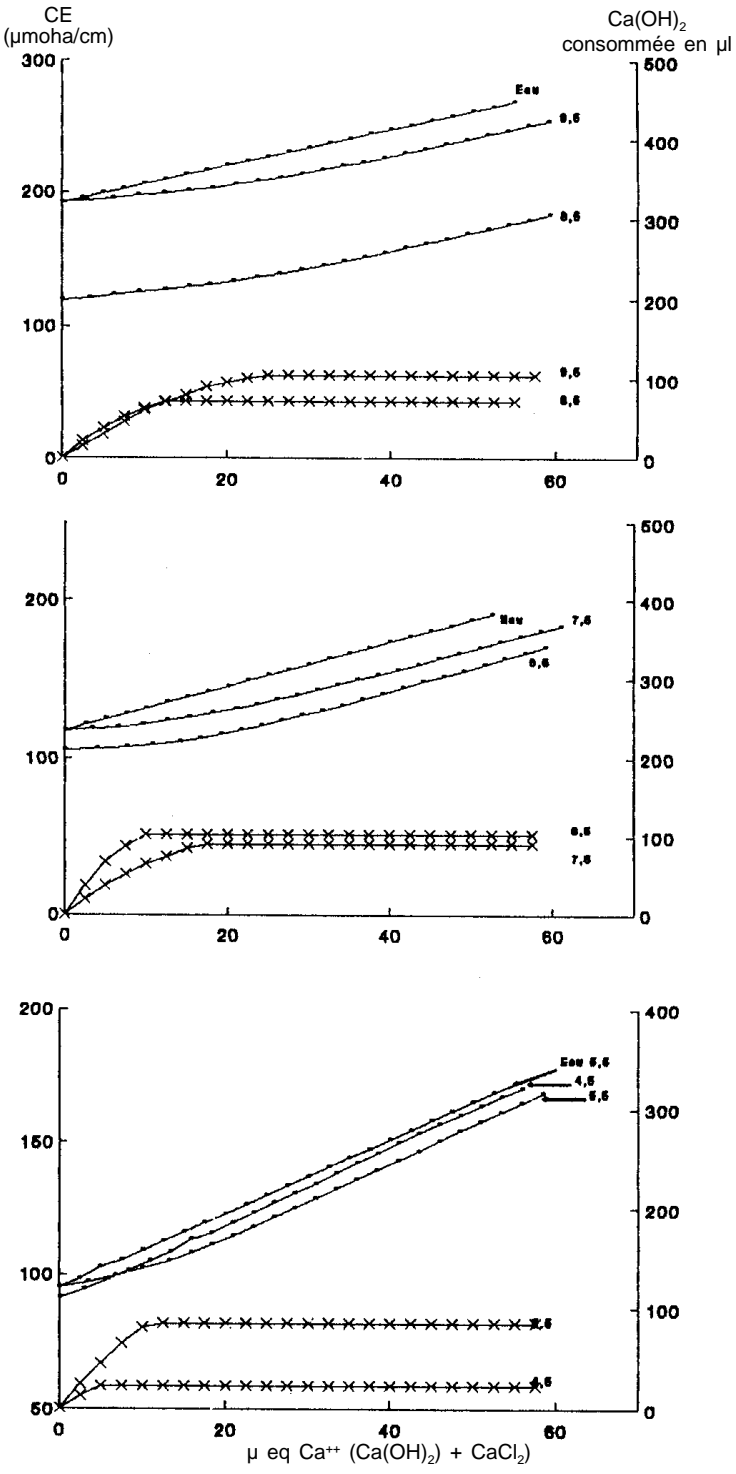

Figure 3. Conductimetric and $\mathrm{Ca}(\mathrm{OH})_{2}$ consumption curves of fulvic acid at different $\mathrm{pH}$.

\section{Conclusion}

Potentiometric and conductimetric titrations provides an acceptable and easy method to study calcium complexation by humic matter. Results found gives evidences for $\mathrm{Ca}$ humic and Ca-fulvic complex formation at different $\mathrm{pH}$ : slightly acid, neutral and basic $\mathrm{pH}$. Both strong acidic $\mathrm{COOH}$ and week $\mathrm{COOH}$ are involved in the formation of such complexes. The stability of the complexes is $\mathrm{pH}$ dependent. It deserve further interest as the mechanisms involved are still limited to hypothesis.
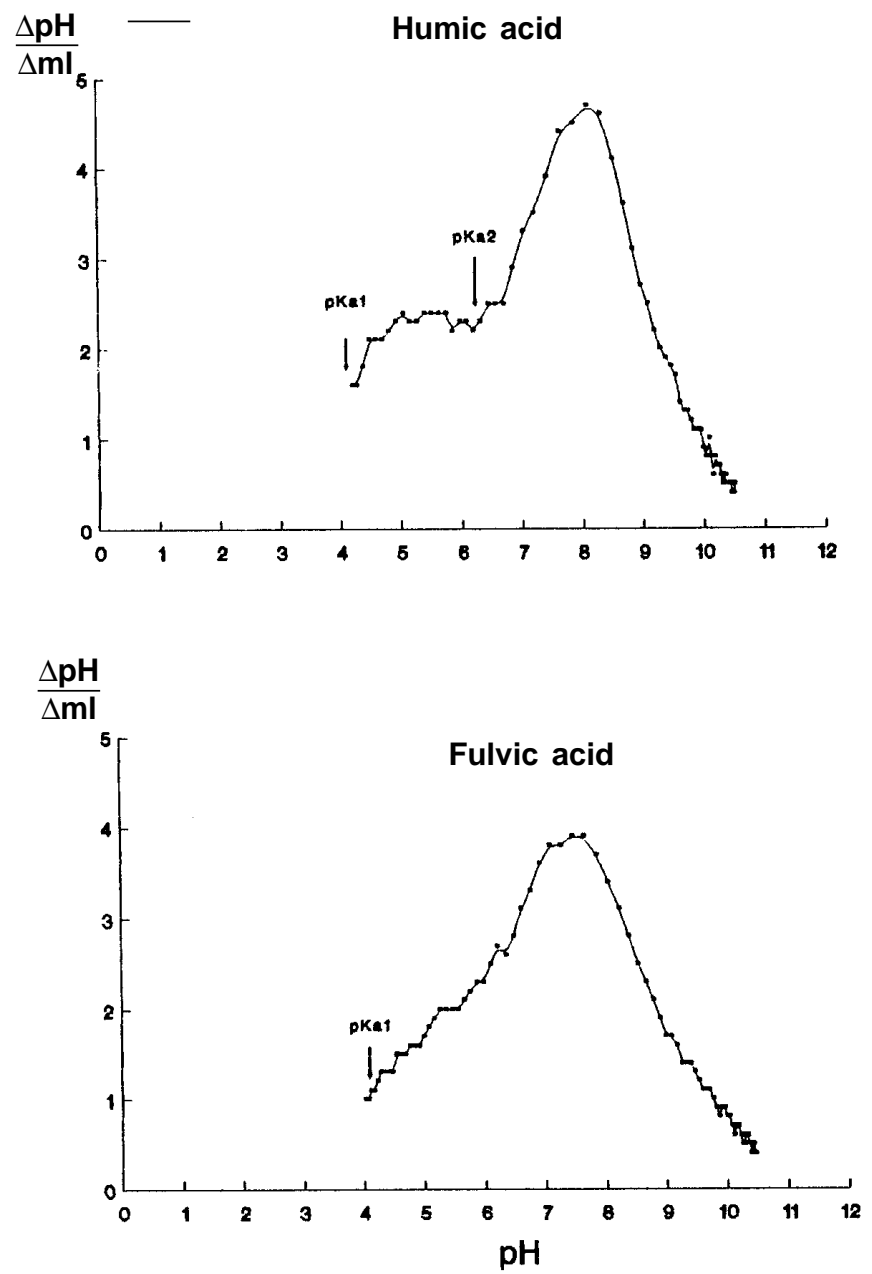

Figure 4. Firts derivative of $\mathrm{NaOH}$ potentiometric curve.

\section{Acknowledgments}

This work was supported in part by the projet J.E.R 6013/ AUPELF.

\section{References}

1. Bollag, J. M.; Loll, M. J. Experientia 1983, 39, 1221-1231.

2. Flaig, W.; Nagar, B.; Scochting, H.; Tietjen, C. FAO soil Bull. 1977, 35, 4-9.

3. Amoros, B.; Andre, L.; Lacout, L. J. C. R. C. R. Acad. Sci. 303-II(13), 1355-1358.

4. Garcia-Mina, J. M.; Sanchez-Diaz, M.; Iniguez. Proceeding of the $\mathrm{I}^{\text {th }}$ Working Meeting of Humic substances, Toulouse, 1997.

5. Garapin, G. Thèse Doctorat INP-ENSA, Toulouse, 1989.

6. Rouquet, N. C. R. Acad .Sci. 1988, 307-II, 1419-1424.

7. Fox, T.; Comeford, N.; Mcfee, W. Soil Sci. Soc. Amer. J. 1990, 54, 1763-1447.

8. Gerk, J. Z. Planzenernähr. Bodenk. 1993, 156, 253-257. 
9. Gaur, A. C. Agrochimica I 1969, XIX, 62-65.

10. Inskeep, W. P.; Silvertooth, J. C. Soil Soc. Sci. Amer. J. 1989, 52, 941-947.

11. Lobartiny, J. C.; Pape, C. Commun. Soil Sci. Plant Anal. 25, 2355-2369.

12. Arai, S.; Kumada K. Geoderma 1977, 19, 307-317.

13. Brun, G.; Sayag, D. R.; Andre L. Humic substances in the global environnement and implication on human heath, 1994, pp 193-198.
14. Aplincourt, M.; Bee-Debras, A.; Prudhome, J. C. Sciences $d u$ sol 1988, 26(3), 157-168.

15. Piccolo, A.; Stevenson, F. J. Geoderma 1982, 27, 195-208.

16. Khalili, F. Soil Science 1990, 150(3), 565-570.

17. Dempsey, B. A.; O'Melia, C. R. Aquatic and Terrestrial Humic Materials ANN. ARBOR Sciences, 1983.

18. Hafidi, M. Thèse Doctorat INP-ENSA, Toulouse, 1990.

19. Takamatsu, T.; Yoshida, T. Soil Sci. 1978, 136(6), 371-381. 